\title{
PLASMA AND URINE URIC ACID LEVELS: HERITABILITY ESTIMATES AND CORRELATION WITH IQ
}

\author{
Kyung-Sook PARK, Eiji INOUYe, and Akio ASAKA \\ Institute of Brain Research, School of Medicine, \\ University of Tokyo, Tokyo 113, Japan
}

\begin{abstract}
Summary Plasma and urine uric acid levels were measured in 37 pairs of twins aged 11 or 12 years and their parents. Effect of age differed between sexes and between plasma and urine. Assuming linear regression on age, the uric acid levels were adjusted for a fixed age, then standardized with mean 0 and standard deviation 1 . The standardized values for plasma yielded a high $\mathrm{MZ}$ twin correlation (0.8429), a high mid-parent-offspring regression (0.7516) and a high parent-offspring regression (0.5100). Because of a high husband-wife correlation (0.3771) a model was used for estimating parameters, where effects of assortative mating and/or common within-family environment were incorporated. In plasma two sets of estimates were obtained: $V_{A} / V_{P}=0.7064,0.3251 ; V_{D} / V_{P}=0.1010,0.1769$; and $V_{E C}$ (variance due to common within-family environment) $/ V_{P}=0.0362$, 0.3416. In urine $V_{A} / V_{P}=0.4125, V_{D} / V_{P}=0.3556$ and $V_{E C} / V_{P}=-0.1106$. It was concluded that heritability of uric acid level was not less than 0.3 in plasma and not less than 0.4 in urine. The plasma uric acid level and IQ was positively correlated (between 0.17 and 0.34 ), but not significant.
\end{abstract}

\section{INTRODUCTION}

Apart from studies on hyperuricemias, there have been reported a few genetic studies on the level of plasma, serum or urine uric acid in normal subjects. Jensen et al. (1965) reported that plasma uric acid level in twins living together or apart was influenced by genetic as well as environmental factors. Boyle et al. (1967) found that genetic component in the control of serum uric acid level was significant only in female twins. Rich et al. (1978) suggested that X-linked genetic factors played a significant role in determining the level of serum uric acid, using half-sib analysis method. On the other hand, O'Brien et al. (1966) and Gulbrandsen et al. (1979) reported a low heritability of serum or plasma uric acid level, applying either of estimates from parent-offspring regression or path analysis method. Apparently 
non-genetic factors are associated with plasma, serum and urine uric acid levels. They include nutrition such as nucleic acid, purines and protein (Waslien et al., 1968; Clifford et al., 1976; Seegmiller et al., 1963; Rauch-Janssen et al., 1977), alcohol consumption (Lieber et al., 1962; Brooks and Mueller, 1966; Saker et al., 1967; Gulbrandsen et al., 1979), body weight, obesity or body surface (Dunn et al., 1963; Brooks and Mueller, 1966; Sturge et al., 1977; Noppa et al., 1978; O'Brien et al., 1966), social status or occupation (Dunn et al., 1963; Montoye et al., 1967), and education (Dunn et al., 1963).

Plasma, serum or urine uric acid level is also reported to be associated with intellectual performance (Stetten and Hearon, 1959; Dunn et al., 1963) and behavior variables (Brooks and Mueller, 1966). It is thus suggested that there might be an association between uric acid level in body fluids and behavioral characteristics due to genetic origin, since there are accumulated evidences that some behavioral characteristics including activity (e.g. Inouye, 1953) and IQ (e.g. Erlenmeyer-Kimling and Jarvik, 1963) are influenced by genetic factors.

Present study aims at estimation of heritability of plasma and urine uric acid levels in a population of twins and their parents, applying a model incorporating the effect of assortative mating and the effect of within-family common environment. Sex and age effects and the correlations of uric acid levels with IQ, weight and height in twins were also examined.

\section{MATERIAL AND METHODS}

There are two samples of subjects, both consisting of twins of age 11 or 12 years and their parents. Twins are those who applied to the Junior High School of the Faculty of Education, University of Tokyo. Subjects of the first sample were obtained in 1978 which consist of 14 monozygotic (MZ) and 2 same-sexed dizygotic (DZ) twin pairs, an opposite-sexed dizygotic pair, 15 fathers and 14 mothers. Second sample was obtained in 1979 which consists of $18 \mathrm{MZ}$ and 2 same-sexed DZ twin pairs, 18 fathers and 20 mothers. All twin subjects were selected for the area of residence, and those with low academic achievements were excluded. They were physically normal and in good health. Zygosity of twins was diagnosed by two methods of Inouye $(1956,1962)$. Informed consent was given by the subjects and school administration.

For each year, heparinized blood was taken in a morning. Fasting urine specimens were also collected in the same morning. Uric acid assay was made on the same day by a colorimetric method at OD $410 \mathrm{~nm}$, using Boehringer Mannheim uric acid uricase color test. Standard solution was $6 \mathrm{mg} / \mathrm{dl}$. Results of intelligence test (Shin-Tanaka B2 Test) of twins were provided by the school.

\section{The model}

The following model is a part of that proposed by Inouye (1979).

Jpn. J. Human Genet. 
We assume

$$
V_{P}=V_{A}+V_{D}+V_{E C}+V_{E W}
$$

where $V_{P}$ is phenotypic variance, $V_{A}$ additive variance, $V_{D}$ dominance variance, $V_{E C}$ within-family variance, and $V_{E W}$ between-family variance. Four equations (1) to (4) below are used to estimate the above four parameters, where assortative mating was taken into consideration. Here $r$ denotes intra-class correlation, and $b$ regression coefficient.

1. Monozygotic twins (MZ) living together

$$
r_{\mathrm{MZ}}=\mathrm{V}_{\mathrm{A}}+\mathrm{V}_{\mathrm{D}}+\mathrm{V}_{\mathrm{EC}} \text {. }
$$

\section{Husband-wife}

Let $A$ additive value, $D$ dominance deviation. $E_{C}$ (within-family environmental deviation) is devided into $\mathrm{E}_{\mathrm{C}_{1}}$ (common environment between husband and wife before marriage having effects lasting to the time of examination) and $E_{\mathrm{C}_{2}}$ (common environment between husband and wife after marriage having the same effects). Intra-class correlation coefficient of husband and wife at the time of marriage is

$$
\rho=\left(\operatorname{Cov} A_{H} A_{W}+\operatorname{CovD}_{H} D_{W}+\operatorname{CovE}_{\mathrm{ClH}} E_{\mathrm{ClW}}\right) \div 0.5\left(\mathrm{~V}_{\mathrm{PH}}+\mathrm{V}_{\mathrm{PW}}\right),
$$

where $H$ denotes husband, and $W$ wife. Intra-class correlation coefficient at the time of examination is

$$
r_{\mathrm{HW}}=\left(\operatorname{CovA}_{\mathrm{H}} \mathrm{A}_{\mathrm{W}}+\operatorname{CovD}_{\mathrm{H}} \mathrm{D}_{\mathrm{W}}+\operatorname{CovE}_{\mathrm{C} 1 \mathrm{H}} \mathrm{E}_{\mathrm{C} 1 \mathrm{~W}}+\operatorname{CovE}_{\mathrm{C}_{2} \mathrm{H}} \mathrm{E}_{\mathrm{C} 2 \mathrm{~W}}\right) \div 0.5\left(\mathrm{~V}_{\mathrm{PH}}^{\prime}+\mathrm{V}_{\mathrm{PW}}^{\prime}\right)
$$

We assume

$$
\mathrm{V}_{\mathrm{PH}}+\mathrm{V}_{\mathrm{PW}}=\mathrm{V}_{\mathrm{PH}}^{\prime}+\mathrm{V}_{\mathrm{PW}}^{\prime}
$$

and

$$
\mathrm{V}_{\mathrm{PH}}=\mathrm{V}_{\mathrm{PW}}
$$

Then

$$
r_{\mathrm{HW}}=\rho+\mathrm{V}_{\mathrm{EC} 2} \div 0.5\left(\mathrm{~V}_{\mathrm{PH}}+\mathrm{V}_{\mathrm{PW}}\right)=\rho+\mathrm{V}_{\mathrm{EC} 2} \div \mathrm{V}_{\mathrm{P}}
$$

3. Mid-parent-offspring

We assume

$\mathrm{E}_{\mathrm{C} 1}=0$. Assortative mating has no effect (Reeve, 1956), and there is no contribution of dominance deviation.

Let $\overline{\mathrm{P}}$ the mean of phenotypic deviations of the parents, 
then

$$
\begin{aligned}
& \overline{\mathrm{P}}=0.5\left(\mathrm{~A}_{\mathrm{F}}+\mathrm{A}_{\mathrm{M}}+2 \mathrm{E}_{\mathrm{C} 2}+\mathrm{E}_{\mathrm{WF}}+\mathrm{E}_{\mathrm{WM}}\right) \text {, and } \\
& \mathrm{V}_{\overline{\mathrm{P}}}=0.25 \mathrm{~V}_{\mathrm{AF}}+0.25 \mathrm{~V}_{\mathrm{AM}}+\mathrm{V}_{\mathrm{EC} 2}+0.25 \mathrm{~V}_{\mathrm{EWF}}+0.25 \mathrm{~V}_{\mathrm{EWM}}
\end{aligned}
$$

where $\mathrm{F}$ denotes father, and $\mathrm{M}$ mother.

Since $E_{W}$ is random, we assume

$$
0.25 \mathrm{~V}_{\mathrm{EWF}}+0.25 \mathrm{~V}_{\mathrm{EWM}}=0.5 \mathrm{~V}_{\mathrm{EW}}
$$

and

$$
\mathrm{V}_{\mathrm{AF}}=\mathrm{V}_{\mathrm{AM}}
$$

Then

$$
\mathrm{V}_{\overline{\mathrm{P}}}=0.5 \mathrm{~V}_{\mathrm{A}}+\mathrm{V}_{\mathrm{EC}^{2}}+0.5 \mathrm{~V}_{\mathrm{EW}}=0.5 \mathrm{~V}_{\mathrm{P}}+\mathrm{V}_{\mathrm{EC} 2}
$$

Since

$$
\operatorname{Cov} \overline{\mathrm{PO}}=\operatorname{Cov} 0.5 \mathrm{~A}_{\mathrm{F}} \mathrm{A}_{\mathrm{O}}+\operatorname{Cov} 0.5 \mathrm{~A}_{\mathrm{M}} \mathrm{A}_{\mathrm{O}}+\operatorname{CovE}_{\mathrm{C} 2} \mathrm{E}_{\mathrm{C} 2}
$$

and

$$
\operatorname{Cov} A_{F} A_{O}=\operatorname{Cov} A_{M} A_{O}=0.5 V_{A} .
$$

Then

$$
\begin{aligned}
b_{\overline{\mathrm{P}} \mathrm{O}} & =\text { CovPO } \div \mathrm{V}_{\overline{\mathrm{P}}}=\left(0.25 \times 2 \mathrm{~V}_{\mathrm{A}}+\mathrm{V}_{\mathrm{EC} 2}\right) \div\left(0.5 \mathrm{~V}_{\mathrm{P}}+0.5 \mathrm{~V}_{\mathrm{EC} 2}\right) \\
& =\left(\mathrm{V}_{\mathrm{A}}+2 \mathrm{~V}_{\mathrm{EC} 2}\right) \div\left(\mathrm{V}_{\mathrm{P}}+\mathrm{V}_{\mathrm{EC} 2}\right)
\end{aligned}
$$

4. Parent-offspring

According to Fisher (1918; see also Crow and Felsenstein, 1968),

$$
b_{\mathrm{PO}}=\left(0.5 \mathrm{~V}_{\mathrm{A}}+\mathrm{V}_{\mathrm{EC}}+0.5 \rho \mathrm{V}_{\mathrm{A}}\right) \div \mathrm{V}_{\mathrm{P}}
$$

\section{RESULTS}

The mean and standard deviation of plasma and urine uric acid levels are shown in Tables 1 and 2. Plasma uric acid level is higher in males than in females, except in twins in the 1979 sample. The sex difference in twin is significant in the 1978 sample, but not in the 1979 sample, if first- and second-born twins are pooled $(t=2.66, p<0.025$ and $t=-1.27, n s$, respectively). In parents sex difference of plasma uric acid level is significant in both samples $(t=4.78, p<0.001$ and $t=6.19$, $\mathrm{p}<0.001$, respectively). On the other hand urine uric acid indicated a sex difference only in the 1979 sample, male twins being lower than female twins $(t=-2.27, p<$ $0.05)$, but fathers being higher than mothers $(\mathrm{t}=2.52, \mathrm{p}<0.025)$. 
Table 1. The mean and standard deviation of plasma uric acid (mg/dl).

\begin{tabular}{|c|c|c|c|c|c|c|}
\hline & \multicolumn{3}{|c|}{1978 sample } & \multicolumn{3}{|c|}{1979 sample } \\
\hline & No. & Mean $\perp$ SD & Min-Max & No. & Mean $\perp S D$ & Min-Max \\
\hline \multicolumn{7}{|l|}{ Males } \\
\hline 1st-born twins & 10 & $4.17 \pm 1.53$ & $2.09-7.57$ & 8 & $3.51 \pm 1.07$ & $2.31-5.51$ \\
\hline 2nd-born twins & 10 & $3.70 \pm 1.40$ & $1.57-6.23$ & 8 & $3.81 \pm 1.57$ & $1.54-6.67$ \\
\hline 1st +2 nd twins & 20 & $3.93 \pm 1.44$ & $1.57-7.57$ & 16 & $3.66 \pm 1.30$ & $1.54-6.67$ \\
\hline Fathers & 15 & $4.81 \pm 1.62$ & $1.99-8.74$ & 18 & $5.89 \pm 1.50$ & $2.65-8.98$ \\
\hline \multicolumn{7}{|l|}{ Females } \\
\hline 1st-born twins & 5 & $2.46 \pm 0.99$ & $1.21-3.78$ & 12 & $4.17 \pm 1.23$ & $1.97-6.26$ \\
\hline 2nd-born twins & 7 & $2.72 \pm 1.39$ & $0.42-4.43$ & 12 & $4.07 \pm 0.74$ & $2.27-4.79$ \\
\hline $1 \mathrm{st}+2$ nd twins & 12 & $2.61 \pm 1.19$ & $0.42-4.43$ & 24 & $4.12 \pm 0.99$ & $1.97-6.26$ \\
\hline Mothers & 14 & $2.46 \pm 0.95$ & $0.98-4.27$ & 20 & $3.44 \pm 0.78$ & $2.24-5.32$ \\
\hline
\end{tabular}

Table 2. The mean and standard deviation of urine uric acid $(\mathrm{mg} / \mathrm{dl})$.

\begin{tabular}{|c|c|c|c|c|c|c|}
\hline & \multicolumn{3}{|c|}{1978 sample } & \multicolumn{3}{|c|}{1979 sample } \\
\hline & No. & Mean $=S D$ & Min-Max & No. & Mean $\perp S D$ & Min-Max \\
\hline \multicolumn{7}{|l|}{ Males } \\
\hline 1st-born twins & 11 & $35.68 \pm 15.48$ & $18.77-69.72$ & 8 & $56.65 \pm 13.72$ & $40.51-76.52$ \\
\hline 2nd-born twins & 10 & $34.09 \pm 15.04$ & $17.77-70.73$ & 8 & $53.64 \pm 18.17$ & $26.74-73.87$ \\
\hline $1 s t+2$ nd twins & 21 & $34.92 \pm 14.91$ & $17.77-70.73$ & 16 & $55.15 \pm 15.63$ & $26.74-76.52$ \\
\hline Fathers & 16 & $31.74 \pm 15.97$ & $5.10-60.34$ & 18 & $57.25 \pm 18.36$ & $23.30-86.80$ \\
\hline \multicolumn{7}{|l|}{ Females } \\
\hline 1st-born twins & 6 & $43.18 \pm 18.06$ & $26.82-74.08$ & 12 & $69.76 \pm 19.98$ & $27.66-95.44$ \\
\hline 2 nd-born twins & 7 & $41.99 \pm 12.22$ & $26.15-62.68$ & 12 & $67.05 \pm 19.74$ & 29. 39-95. 10 \\
\hline $1 s t+2 n d$ twins & 13 & $42.54 \pm 14.52$ & $26.15-74.08$ & 24 & $68.41 \pm 19.48$ & $27.66-95.44$ \\
\hline Mothers & 16 & $38.40 \pm 18.70$ & $12.74-81.45$ & 20 & $42.67 \pm 17.30$ & $10.85-68.81$ \\
\hline
\end{tabular}

As to the effect of age on plasma uric acid level, fathers indicated a higher mean than male twins, but mothers indicated a lower mean than females twins, suggesting an increase of the level with age in males and a decrease in females. In urine twins indicated a higher mean than parents except in males of the 1979 sample. Assuming linear regression of uric acid level on age, analysis was made separately for each sex and each sample. The result is shown in Table 3, which also shows correlation coefficient between uric acid level and age. It is seen in Table 3 that regression coefficient of plasma uric acid level on age is positive in males and negative in females, and correlation coefficients are significant in both sexes 
in the 1979 sample. In urine decrease of uric acid level with age is significant in females in the 1979 sample.

Next the values were adjusted for age of 150 months, separately for each sex and each sample, using equations in Table 3. The age-adjusted values were then standardized by

$$
\mathrm{z}=(\mathrm{x}-\overline{\mathrm{x}}) / \sigma
$$

again separately for each sex and each sample ( $\mathrm{x}$ is the age-adjusted value, $\bar{x}$ and $\sigma$ are mean and standard deviation of $\mathrm{x}$ ).

Correlations and regressions of the age-adjusted and standardized values are shown in Tables 4 and 5, which suggest a high heritability of plasma uric acid level, if husband-wife correlation was disregarded. When we apply the model for husband-wife correlation (equation (2)), we obtain two values of $\rho$ (0.3415 and 0.0361) and therefore two values of $V_{E C} / V_{P}(0.0362$ and 0.3416$)$ for plasma uric acid level. Putting these values to equations for mid-parent-offspring regression (3) and parentoffspring regression (equation (4)), we obtain $V_{A} / V_{P}=0.7064$ and 0.3251 . Corresponding $\mathrm{V}_{\mathrm{D}}$ values derived from equation for $\mathrm{MZ}$ twin correlation (1) are 0.1010 and 0.1769 .

In urine two values of $\rho$ are 0.3140 and -0.0616 , and corresponding $V_{E C} / V_{P}$ values are -0.1106 and 0.2650 , but the second values yielded a minus value of $\mathrm{V}_{\mathrm{A}} / \mathrm{V}_{\mathrm{P}}$, thus were disregarded. From the first values $\mathrm{V}_{\mathrm{A}} / \mathrm{V}_{\mathrm{P}}$ is estimated to be 0.4125 , and $V_{D} / V_{P}$ 0.3556. The above results are summarized in Fig. 1.

Table 3. Regression of uric acid level(y) on age in months $(\mathrm{x})$.

\begin{tabular}{|c|c|c|c|c|}
\hline & No. & & $\begin{array}{l}\text { Correlation } \\
\text { coefficient }\end{array}$ & Probability \\
\hline \multicolumn{5}{|l|}{ Plasma } \\
\hline \multicolumn{5}{|l|}{1978 sample } \\
\hline Male & 35 & $y=0.0022 x+3.6335$ & 0.2640 & ns \\
\hline Female & 26 & $y=-0.0003 x+2.6392$ & -0.0524 & ns \\
\hline \multicolumn{5}{|l|}{1979 sample } \\
\hline Male & 34 & $y=0.0055 x+2.8584$ & 0.6325 & 0.001 \\
\hline Female & 44 & $y=-0.0016 x+4.3201$ & -0.3112 & 0.05 \\
\hline \multicolumn{5}{|l|}{ Urine } \\
\hline \multicolumn{5}{|l|}{1978 sample } \\
\hline Male & 37 & $y=-0.0060 x+35.4113$ & -0.0754 & ns \\
\hline Female & 29 & $y=-0.0097 x+43.4675$ & -0.0975 & ns \\
\hline \multicolumn{5}{|l|}{1979 sample } \\
\hline Male & 34 & $y=0.0064 x+53.9329$ & 0.0789 & ns \\
\hline Female & 44 & $y=-0.0715 x+79.1967$ & -0.5931 & 0.001 \\
\hline
\end{tabular}


Table 4. Intra-class correlation $(r)$ and regression $(b)$ for plasma uric acid level, age-adjusted and standardized.

\begin{tabular}{lccc}
\hline & No. & $\begin{array}{c}\text { Intra-class } \\
\text { correlation }\end{array}$ & Regression \\
\hline MZ & 16 & $r=0.8478^{* * *}$ & \\
Male & 15 & $r=0.8386^{* * *}$ & \\
Female & 31 & $r=0.8429 * * *$ & \\
Male+Female & 62 & & $b=0.7516$ \\
Mid-parent-offspring & 130 & & $b=0.5100$ \\
Parent-offspring & 32 & & $b=0.6070$ \\
Father-son & 32 & & $b=0.5878$ \\
Father-daughter & 34 & & $b=0.3461$ \\
Mother-son & 32 & $b=0.4909$ \\
Mother-daughter & 31 & & \\
Husband-wife & & & \\
\hline
\end{tabular}

$* \mathrm{p}<0.05, * * \mathrm{p}<0.01, * * * \mathrm{p}<0.001$.

Table 5. Intra-class correlation $(r)$ and regression $(b)$ for urine uric acid level, age-adjusted and standardized.

\begin{tabular}{lccc}
\hline & No. & $\begin{array}{l}\text { Intra-class } \\
\text { correlation }\end{array}$ & Regression \\
\hline MZ & 17 & $r=0.6459^{*}$ & \\
$\quad$ Male & 15 & $r=0.6452^{*}$ & \\
$\quad$ Female & 32 & $r=0.6465^{* *}$ & $b=0.2152$ \\
$\quad$ Male+Female & 68 & & $b=0.1468$ \\
Mid-parent-offspring & 140 & & $b=0.0493$ \\
Parent-offspring & 35 & & $b=0.1297$ \\
Father-son & 33 & & $b=0.2368$ \\
Father-daughter & 37 & & $b=0.1675$ \\
Mother-son & 35 & $r=0.2028$ & \\
Mother- daughter & 34 & & \\
Husband-wife & & & \\
\hline
\end{tabular}

${ }^{*} \mathrm{p}<0.01, * * \mathrm{p}<0.001$.

The mean and standard deviation of IQ are $129 \pm 19$ in male and $116 \pm 16$ in female twins in the 1978 sample, sex difference being not significant. In the 1979 sample corresponding values are $117 \pm 11$ and $124 \pm 14$ without sex difference.

Positive but not significant correlations are seen between plasma uric acid level and IQ in twins, where both values are standardized $(r=0.3408, n=27$ in 

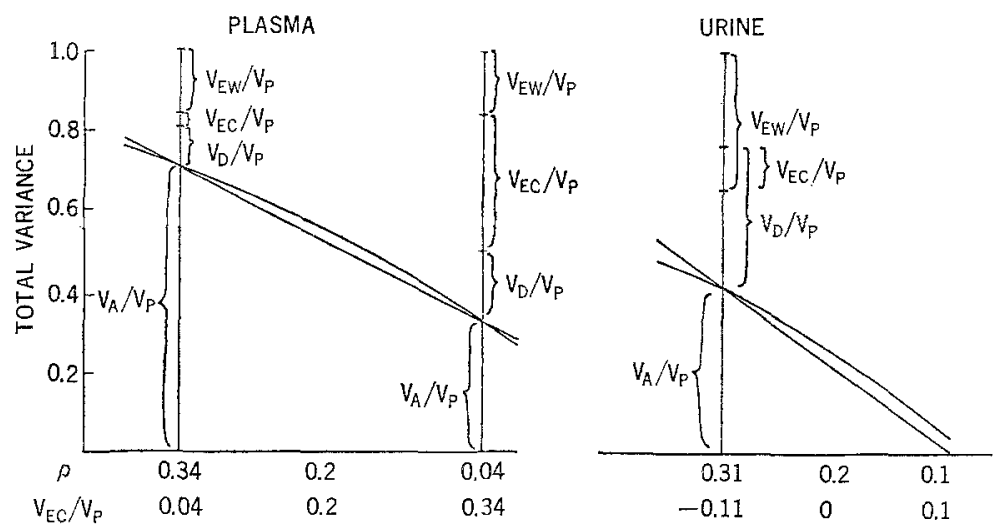

Fig. 1. Estimated components of uric acid phenotypic variance.

males; $r=0.1719, n=25$ in females and $r=0.2482, n=52$ in all twins). As to correlation between standardized urine uric acid and IQ it is negative in females ( $\mathrm{r}=$ $-0.3139, \mathrm{n}=25)$ and positive in males $(\mathrm{r}=0.1428, \mathrm{n}=27)$, both are not significant.

The non-adjusted and non-standardized plasma uric acid level reveal nonsignificant correlations with body weight in female twins $(r=0.1542, n=36)$ as well as in male twins $(\mathrm{r}=-0.0221, \mathrm{n}=36$ ). In urine correlations with weight are nonsignificant both in male and female twins $(\mathrm{r}=-0.2750, \mathrm{n}=37 ; \mathrm{r}=0.0713, \mathrm{n}=37$, respectively). Similarly correlations with height were also non-significant in plasma and urine in both sexes.

\section{DISCUSSION}

The present study is in agreement with previous reports in that males had a higher mean level than females (Rich et al., 1978; Jensen et al., 1965; Seegmiller et al., 1963; O'Brien et al., 1966; Mikkelsen et al., 1965). In males a positive age effect on plasma uric acid level was revealed, but it was negative in females. Several studies have shown that age as well as sex are related to serum uric acid level. Mikkelsen et al. (1965) reported that the mean serum uric acid level of the age of pre-puberty was different from that of the age of puberty in both sex. Dunn et al. (1963) reported that there was no evidence of an age effect in adult population.

As to heritability $\left(=V_{A} / V_{P}\right)$ of plasma uric acid level it seems to be quite high because of a high $\mathrm{MZ}$ twin correlation, a high mid-parent-offspring regression and a high parent-offspring regression (from Table 4 they are $0.8429,0.7516$ and 0.5100 , respectively). However, a considerable amount of husband-wife correlation was revealed (0.3771), and therefore, the effects of assortative mating and/or common within-family environment were examined, applying the model incorporating the two variables. This analysis yielded two sets of estimates. One is a high heritability (0.7064) with a considerable phenotypic correlation between husband and 
wife $(\rho=0.3415)$, a low ratio of common environmental variance to phenotypic variance $\left(\mathrm{V}_{\mathrm{EC}} / \mathrm{V}_{\mathrm{P}}=0.0362\right)$, and a low ratio of dominance variance to phenotypic variance $\left(V_{D} / V_{P}=0.1010\right)$. The other is a medium heritability $(0.3251)$ with a low phenotypic correlation between husband and wife $(0.0361)$, a medium $V_{E C} / V_{P}$ $(0.3416)$ and a low $V_{D} / V_{P}(0.1769)$. It seems that there is no evidence as to which estimate is more accurate.

Inouye et al. (1979) reported a high heritability of plasma uric acid level of around 0.8 or 0.9 , applying half-sib analysis method. In this study a minus husband-wife phenotypic correlation $(\rho=-0.2411)$ was reported and $V_{E C} / V_{P}$ had also a minus sign. This and the present studies disagree in several point, and it is premature to draw a definite conclusion.

As to urine uric acid level heritability was estimated to be around 0.4. A medium amount of $\rho$ was seen (around 0.3 ), and $\mathrm{V}_{\mathrm{EC}} / \mathrm{V}_{\mathrm{P}}$ had a minus sign. Rather strange is a considerable amount of $V_{D} / V_{P}$ (around 0.35). Corresponding values in the half-sib study were $\mathrm{V}_{\mathrm{A}} / \mathrm{V}_{\mathrm{P}} \doteqdot 0.8, \rho \fallingdotseq 0$, and $\mathrm{V}_{\mathrm{EC}} / \mathrm{V}_{\mathrm{P}} \doteqdot 0.1$, but $\mathrm{V}_{\mathrm{D}} / \mathrm{V}_{\mathrm{P}}$ was not estimated. Again two studies disagree. Conservative conclusion would be that heritability of uric acid level is not less than 0.3 in plasma and not less than 0.4 in urine, but the effects of assortative mating and/or within-family common environment are to be evaluated in future.

As to correlation between uric acid level and IQ, plasma indicated a positive correlation of the magnitude between 0.17 and 0.34 , though not significant. In urine unequivocal result was not obtained. Similarly, correlation between uric acid level and non-genetic factors was equivocal. Further studies on a larger sample are clearly needed.

\section{REFERENCES}

Boyle, J.A., Greig, W.R., Jasani, M.K., Duncan, A., Diver, M., and Buchanan, W.W. 1967. Relative roles of genetic and environmental factors in the control of serum uric acid levels in normouricaemic subjects. Ann. Rheum, Dis. 26: 234-238.

Brooks, G.W., and Mueller, E. 1966. Serum urate concentrations among university professors: Relation to drive, achievement, and leadership. JAMA 195: 415-418.

Clifford, A.J., Riumallo, J.A., Young, V.R., and Scrimshaw, A.S. 1976. Effect of oral purines on serum and urinary uric acid of normal, hyperuricemic and gouty humans. J. Nutr. 106: 428450 .

Crow, J.F., and Felsenstein, J. 1968. The effect of assortative mating on the genetic composition of a population. Engen. Quart. 15: 85-97.

Dunn, J.P., Brooks, G.W., Mausner, J., and Rodnan, G.P., and Cobb, S. 1963. Social class gradient of serum uric acid levels in males. JAMA 185: 431-436.

Erlenmeyer-Kimling, L., and Jarvik, L.F. 1963. Genetics and intelligence: A review. Science 142: 1477-1479.

Gulbrandsen, C.L., Morton, N.E., Rao, C.C., Rhoads, G.G., and Kagan, A. 1979. Determinants of plasma uric acid. Hum. Genet. 50: 307-312.

Inouye, E. 1953. Eine Charakterstudie mittels der Zwillings-methode. Psychiat. Neurol. Jap. (in Japanese) 55: 603-638. 
Inouye, E. 1956. Zygosity diagnosis. Jpn. J. Human Genet. (in Japanese w, English summary) 1: $24-31$.

Inouye, E. 1962. Zygosity diagnosis of Japanese twins by essen-möller's formulas. Studies on Twins Vol. III, Fujita, K. ed., Nihon-Gakujutsu-Shinkikai, Tokyo: 1-13. (in Japanese).

Inouye, E. 1979. Analysis method. In Quantitative genetic studies of normal development and normal traits using half-sib analysis method. Reports of Researches Granted by the Ministry of Education (No. 237054): 7-13 (in Japanese).

Inouye, E., Asaka, A., and Park, K.S. 1979. Genetic variation of enzyme activity. In Quantitative genetic studies of normal development and normal traits using half-sib analysis method. Reports of Researches Granted by the Ministry of Education (No. 237054): 16-21. (in Japanese).

Jensen, J., Blankenhorn, D.H., Chin, H.P., Sturgeon, P., and Ware, A.G. 1965. Serum lipids and serum uric acid in human twins. J. Lipid Res. 6: 193-205.

Lieber, C.A., Jones, D.P., Losowsky, A.S., and Davidson, C.S. 1962. Interrelation of uric acid and ethanol metabolism in man. J. Clin. Invest. 41: 1863-1870.

Mikkelsen, W.M., Dodge, H.J., and Valkenburg, H. 1965. The distribution of serum uric acid values in a population unselected as to gout or hyperuricemia: Tecumseh, Michigan 1959-1960. Am. J. Med. 39: 242-251.

Montoye, H.J., Faulkner, J.A., Dodge, H.J., Mikkelsen, W.M., Willis, P.W., and Block, W.D. 1967. Serun uric acid concentration among business executives with observations on other coronary heart disease risk factors. Ann. Int. Med. 66: 838-850.

Noppa, H., Bengtsson, C., Björntorp, P., Smith, U., and Tibblin, E. 1978. Overweight in womenmetabolic aspects. Acta Med. Scand., 203: 135-141.

O'Brien, W.M., Burch, T.A., and Bunim, J.J. 1966. Genetics of hyperuricaemia in blackfeet and pima indians. Ann. Rheum. Dis, 25: 117-119.

Rauch-Janssen, A., Gröbner, W., and Zöllner N. 1977. Comparison of serum uric acid and urinary uric acid excretion under a soy protein diet low in purines and under a formula diet virtually free of purines. Nutr. Metab. 21 (Suppl. 1): 94-97.

Reeve, E.C.R. 1956. Discussion. Cold Spring Harber Symposia on Quantitative Biology. 20: 76-78.

Rich, R.L., Nance, W.E., Corey, L.A., and Boughman, J.A. 1978. Evidence for genetic factors inffuencing serum uric acid levels in man. Progress in clinical and biological research, Nance, W.E. ed., Alan R. Liss, Inc., New York, 24/C: 187-192.

Saker, B.M., Toffer, O.B., Burvill, M.J., and Reilly, K.A. 1967. Alcohol consumption and gout. Med. J. Aus. 1: 1213-1216.

Seegmiller, J.E., Laster, L., and Howell, R.R. 1963. Biochemistry of uric acid and its relation to gout. N. Engl. J. Med. 268: 712-716.

Stetten, D., Jr., and Hearon, J.E. 1959. Intellectual level measured by army classification battery and serum uric and concentration. Science 129: 1737.

Sturge, R.A., Scott, J.T., Kennedy, A.C., Hart, D.P., and Bunchanan, W.W. 1977. Serum uric acid in England and Scotland. Ann. Rheum. Dis. 36: 420-427.

Waslien, C.I., Calloway, D.H., and Margen, S. 1968. Uric acid production of men fed graded amounts of egg protein and yeast nucleic acid. Am. J. Clin. Nutr. 21 : 892-897. 